\title{
SINTERING EFFECTS ON THE DENSIFICATION OF NANOCRYSTALLINE HYDROXYAPATITE
}

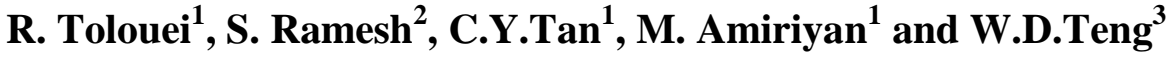 \\ ${ }^{1}$ Ceramics Technology Laboratory \\ University Tenaga Nasional, \\ 43009 Kajang, Selangor, Malaysia \\ ${ }^{2}$ Centre of Advanced Manufacturing \& Material Processing (AMMP), Department of \\ Engineering Design and Manufacture, Faculty of Engineering \\ University of Malaya \\ 50603 Kuala Lumpur, Malaysia \\ Email: ramesh79@um.edu.my \\ ${ }^{3}$ Ceramics Technology Group \\ SIRIM Berhad, 40911 Shah Alam, Selangor, Malaysia
}

\begin{abstract}
The effects of sintering profiles on the densification behaviour of synthesized nanocrystalline hydroxyapatite (HA) powder were investigated in terms of phase stability and mechanical properties. A wet chemical precipitation method was successfully employed to synthesize a high purity and single phase HA powder. Green HA compacts were prepared and subjected to sintering in air atmosphere over a temperature range of $700^{\circ} \mathrm{C}$ to $1300^{\circ} \mathrm{C}$. In this study two different holding times were compared, i.e. 1 minute versus the standard 120 minutes. The results revealed that the 1 minute holding time sintering profile was indeed effective in producing a HA body with high density of $98 \%$ theoretical when sintered at $1200^{\circ} \mathrm{C}$. High mechanical properties such as fracture toughness of $1.41 \mathrm{MPa}^{1 / 2}$ and hardness of $9.5 \mathrm{GPa}$ were also measured for HA samples sintered under this profile. Additionally, XRD analysis indicated that decomposition of the HA phase during sintering at high temperatures was suppressed.
\end{abstract}

Keywords: mechanical properties, bioceramics, hydroxyapatite, sintering.

\section{INTRODUCTION}

The main inspiration behind the use of Calcium Phosphates $(\mathrm{CaP})$ bioceramics as a bone substitute material is the similarity of their composition to the mineral phase of human bone and teeth (Hench, 1998; Legeros and Legeros, 1993). Hydroxyapatite $\mathrm{Ca}_{10}$ $\left(\mathrm{PO}_{4}\right)_{6}(\mathrm{OH})_{2}(\mathrm{HA})$, is one of the principal types of $\mathrm{CaP}$ ceramics found in the human body. However, HA bioceramics have a limited application in load bearing applications due to developed cracks (Gabriel Chu et al., 2002; Muralithran \& Ramesh, 2000). Thus, an optimization of the mechanical properties and microstructure of HA samples through a suitable choice of sintering parameters is under investigation. The sinterability and strength of dense HA is in association with the properties of the starting powder. Various methods have been used for preparation of HA powders, including the wet precipitation method, mechanochemical method, sol gel method and the hydrothermal method (Suchanek \& Yoshimura, 1997). Muralithran and Ramesh (2000) claimed that 
HA is a powder whose synthesis by their novel method could attain high density when sintered without pressure at $1200^{\circ} \mathrm{C}-1300^{\circ} \mathrm{C}$.

A number of different studies were carried out with the aim of improving the mechanical properties of HA by applying appropriate sintering additives or heat treatment for sintering of dense samples (Ramesh et al., 2007; Zhou et al., 1993). One of the critical controlling parameters that must be considered during the processing of hydroxyapatite is the selection of a heat treatment method to obtain a high density HA body (Ramesh, 2008). The conventional pressureless sintering method is the routine technique, in which the powder compacts have been heated at a certain rate, holding at the maximum temperature for several hours before cooling at the same rate as the heating rate (Wei Chen \& Wang, 2000). Simultaneous with high temperature sintering and long holding time, the exaggerated grain coarsening or formation of other phases may take place in HA samples. Zhou et al. (1993) reported that sintering of HA was complicated by two processes, namely dehydroxylation and decomposition of the HA phase at high temperatures. HA, after a dehydroxylation process, starts to decompose into secondary phases such as tricalcium phosphate and tetracalcium phosphate. In that case, the decomposition of HA in air at high temperature hinders sintering and causes a decrease in density. The present work investigates the effect of sintering holding time on the densification behaviour and mechanical properties of nanocrystalline HA.

\section{EXPERIMENTAL PROCEDURES}

The HA nanopowder used in this work was prepared using a novel wet precipitation method (Ramesh, 2004) by reacting calcium hydroxide and orthophosphoric acid at room temperature with the $\mathrm{pH}$ maintained above 10 by the addition of ammonium hydroxide solution. Once the titration process was completed, the suspension was aged overnight. Then, the precipitate was filtered, washed, dried and ground to a powder of high purity, which was composed of pure stoichiometric HA phase. The thus prepared nano HA powder $(<80 \mathrm{~nm})$ was uniaxially pressed at $20 \mathrm{MPa}$ into pellets using a 20 $\mathrm{mm}$ diameter die for disc samples and a $32 \times 13 \mathrm{~mm}$ rectangular die for bar samples. The green compacted samples were subsequently cold isostatically pressed (CIP) at about $200 \mathrm{MPa}$ (Reiken Seiki, Japan). The CIP samples were sintered by a conventional sintering method in air atmosphere at temperatures ranging from $1000^{\circ} \mathrm{C}$ to $1350^{\circ} \mathrm{C}$, in $50^{\circ} \mathrm{C}$ intervals. Sintering heating profiles were carried out with different holding times of 120 minutes and 1 minute using a standard ramp rate of $2^{\circ} \mathrm{C} / \mathrm{min}$. All sintered HA samples were polished to a $1 \mu \mathrm{m}$ surface finish prior to testing. The densities of the sintered samples were measured by the Archimedes methods, with distilled water as the immersion medium. Relative density was calculated by taking the theoretical density of $\mathrm{HA}$ as $3.156 \mathrm{~g} / \mathrm{cm}^{-3}$. The phase analysis of all samples was characterized by using X-ray diffraction (XRD-6000, Shimadzu, Japan). The Young's modulus of the rectangular samples was measured using a sonic resonance instrument (Grindosonic; MK5, Belgium).

The Vickers hardness $\left(\mathrm{H}_{\mathrm{V}}\right)$ and fracture toughness $\left(\mathrm{K}_{\mathrm{Ic}}\right)$ of the sintered discs was determined using a microhardness tester (Wilson Wolpert, 401 MVA). The indentation load (less than $300 \mathrm{~g}$ ) was applied for 10 seconds to the polished surface of the sample. The average diagonal length of the indent was measured 3 times for each sample and the average value was taken. The Vickers hardness was calculated from the method described in the ASTM E1876-97. The Vickers indentation of HA samples causes the creation of crack patterns that can be described mainly according to the median crack 
system. Therefore fracture toughness was calculated using Eq. (1), which is related to the radial crack (Niihara, 1985):

$$
K_{I C}=0.203\left(\frac{c}{a}\right)^{-1.5}\left(H_{V}\right)(a)^{0.5}
$$

where $H_{v}$ is the Vickers hardness, $a$ is the half diagonal of the indentation, $c$ is the radial crack measured from the centre of the indent impression, and $L$ is the crack length.

\section{RESULTS AND DISCUSSION}

The variation in the relative density curves of HA samples with sintering temperatures is shown in Figure 1. The bulk density trend of the 120 minute holding time sintering was in good agreement with that reported in the literature for conventional sintered HA (Ruys et al., 1995; Ramesh et al., 2008). In general, the relative density of HA increased when sintered at higher temperature for holding times of both 1 minute and 120 minutes. It can be noted that sintering with a 120 minute holding time produced HA with higher density than the equivalent 1 minute holding time when sintered at $1000^{\circ} \mathrm{C}$. However, the bulk density of the 1 minute holding time samples attained almost equivalent densities with the 120 minute holding time samples when sintered above $1000^{\circ} \mathrm{C}$. These results shows that it is possible to use a very short holding time to densify the HA body via the conventional pressureless sintering method.

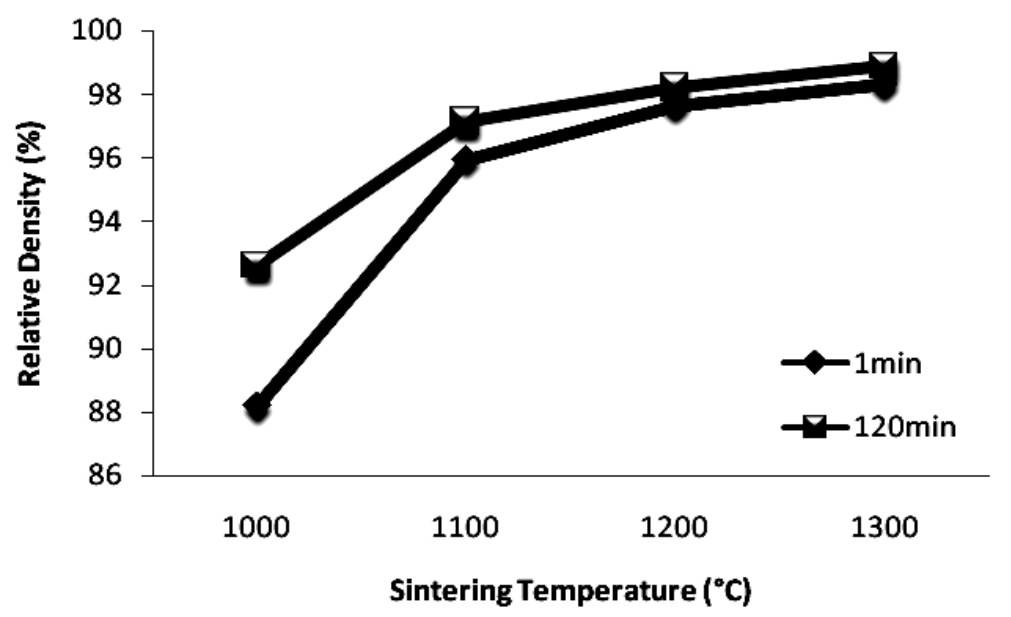

Figure 1. Relative density variation as a function of sintering temperature for HA sintered using two different holding times.

The HA phase sinterability was confimed by XRD phase analysis of the sintered HA samples sintered under both conditions. The sintering of HA samples, regardless of sintering holding time and temperature, revealed the presence of only the HA phase, as shown in Figure 2. In general, high temperature sintering above $1250^{\circ} \mathrm{C}$ of $\mathrm{HA}$ can lead to the partial thermal decomposition of HA into TCP and TTCP (Wang et al. 1993; Newesely, 1977; Liao et al., 1999). However, in the present work, the formation of secondary phases was not detected throughout the sintering regime employed. This observation could be associated with the high local humid atmosphere that could have hindered dehydroxylation in the HA matrix during high temperature sintering. 
Attempts to correlate the Young's modulus with bulk density revealed that a linear relationship exists, as shown in Figure 3. It was found that Young's modulus of the sintered HA increased up to a maximum of $110 \mathrm{GPa}$ with increasing bulk density up to $96 \%$ of theoretical value. The results showed that the HA samples sintered with 1 minute holding time achieved higher Young's modulus values of $119 \mathrm{GPa}$ than samples sintered at the same temperature under the standard 120 minute holding time.

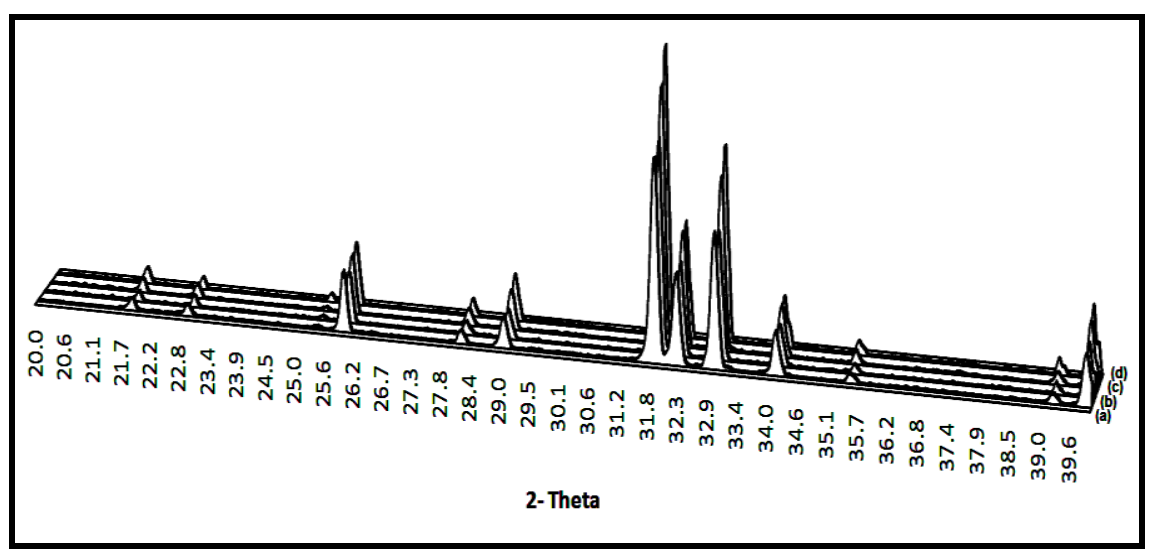

Figure 2. XRD traces of HA samples sintered at (a) $1000^{\circ} \mathrm{C}$ (b) $1100^{\circ} \mathrm{C}$ (c) $1200^{\circ} \mathrm{C}$ (d) $1300^{\circ} \mathrm{C}$ using the one minute holding time.

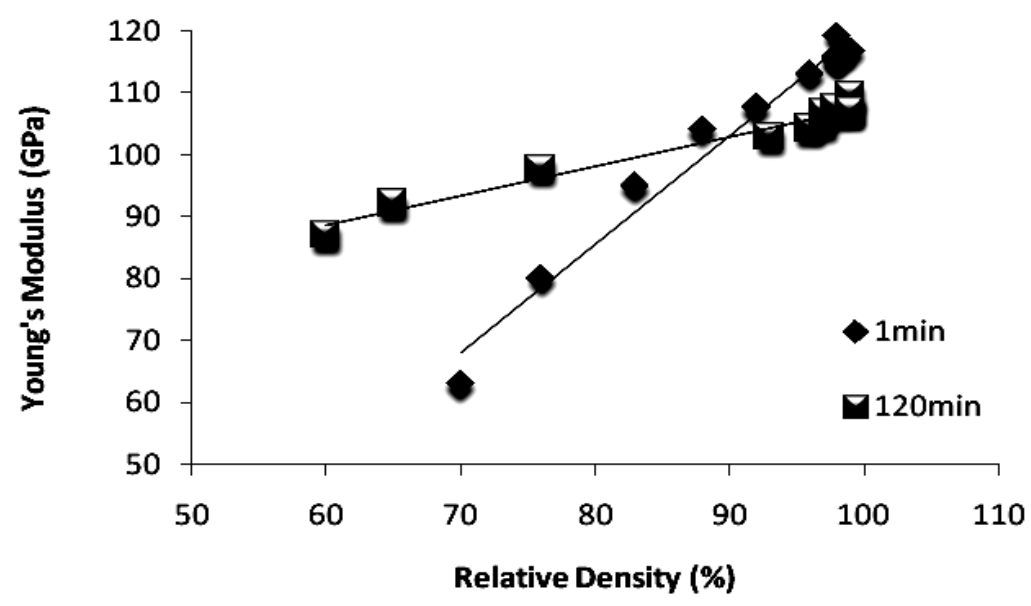

Figure 3. A linear relationship exists between the sintered density and the Young's modulus of HA samples sintered for both sintering profiles.

The effect of sintering temperature on the Vickers hardness for HA sintered with the two different holding times is shown in Figure 4. It can be seen that HA sintered at $1100^{\circ} \mathrm{C}$ using the one minute holding time displayed the highest hardness value of 9.5 $\mathrm{GPa}$, compared to $7.8 \mathrm{GPa}$ for the HA sample sintered using the 120 minute holding time. The increased hardness value for samples sintered up to $1100^{\circ} \mathrm{C}$, as depicted in Figure 4 , could be attributed to an increase in relative density from $88.2 \%$ to $96 \%$, as shown in Figure 1 . However, beyond $1100^{\circ} \mathrm{C}$ the relative density continued to increase slightly, while the hardness value gradually decreased with increasing temperature. This result is in agreement with work of Lu et al. (1998); Metsger et al. (1982), He et al. (2008) and Ramesh et al. (2008), who reported that hardness of HA is controlled by not 
just the bulk density but also the grain size of the sintered body. These authors claimed that below a certain critical grain size the hardness is governed by relative density and above that size grain growth is the controlling parameter.

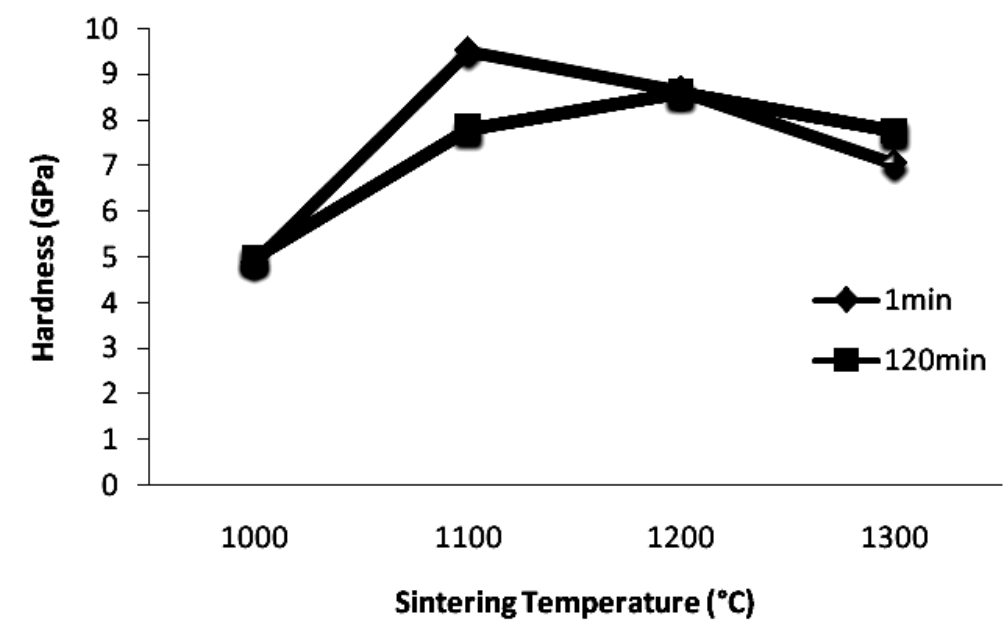

Figure 4. Variation in Vickers hardness with sintering temperature for HA ceramics.

The effect of sintering temperature on the fracture toughness of HA samples sintered using two different holding times is shown in Figure 5. The results show that the fracture toughness of the HA sintered with 1 minute holding time is apparently higher than the HA samples sintered at similar temperature with a 120 minute holding time. The maximum fracture toughness of HA sintered samples with the 120 minute holding time was about $1.05 \pm 0.1 \mathrm{MPa} \cdot \mathrm{m}^{1 / 2}$ and this is in agreement with the work of Suchanek and Yoshimura (1998) and Van Landuyt et al. (1995).

The fracture toughness of HA sintered samples with 1 minute holding time was observed to decrease from $1.41 \pm 0.4$ to $1.12 \pm 0.5 \mathrm{MPa} . \mathrm{m}^{1 / 2}$ with increasing temperature. Gibson et al. (2001) reported a similar decreasing trend for fracture toughness in their HA samples. These authors agreed that the decreasing trend experienced by the sintered samples was associated with grain coarsening. Further work is in progress to elucidate the effects of grain size on the toughness of HA.

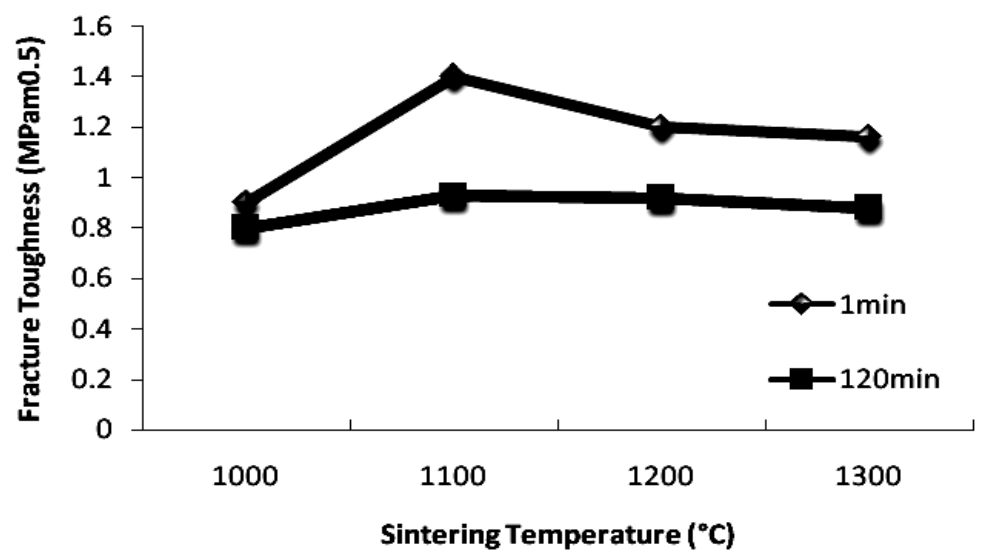

Figure 5. Effect of sintering temperature on the fracture toughness of HA samples. 


\section{CONCLUSIONS}

The effects of a one minute holding time versus the standard 120 minute holding time during sintering on the properties of synthesised nanocrystalline HA were investigated. The results revealed that the one minute holding time sintering profile was indeed beneficial in producing a dense HA body that exhibited enhanced toughness compared to the standard 120 minute holding time. Decomposition of HA to secondary phases was not observed in the present study for the two sintering profiles. Sintering at $1100^{\circ} \mathrm{C}$ and using the one minute holding time resulted in a sintered HA body that exhibited the overall best properties of $98 \%$ density, having high Young's modulus above $110 \mathrm{GPa}$, a high hardness of about $9.5 \mathrm{GPa}$ and an exceptionally high toughness of $1.41 \mathrm{MPa} . \mathrm{m}^{1 / 2}$. It was demonstrated in this work that HA could be densified using a very short holding time via the conventional pressureless sintering method.

\section{ACKNOWLEDGMENTS}

This work was supported by the Ministry of Science, Technology and Innovation of Malaysia (Science Fund Grant No. 03-02-03-SF0073).

\section{REFERENCES}

Gabriel Chu, T.M., Orton, D.G., Hollister, S.J., Feinberg, S.E. and Halloran, J.W. 2002. Mechanical and in vivo performance of hydroxyapatite implants with controlled architectures. Biomaterials, 23: 1283-1293.

Gibson, I.R., Ke, S., Best, S.M. and Bonfield, W. 2001. Effect of powder characteristics on the sinterability of hydroxyapatite powders. Journal of Materials Science: Materials in Medicine, 12: 163-171.

He, L.H., Standard, O.C. Huang, T.T.Y., Latella, B.A. and Swain, M.V. 2008. Mechanical behaviour of porous hydroxyapatite. Acta Biomaterialia, 4: 577586.

Hench, L.L. 1998. Biomaterials: a forecast for the future. Biomaterials, 19: 1419-1423.

LeGeros, R.Z. and LeGeros, J.P. 1993. Dense hydroxyapatite. In: Hench, L.L. and Wilson, J. (eds.) An Introduction to Bioceramics. World Scientific, Singapore, p. 139.

Liao, C., Lin, F., Chen, K. and Sun, J. 1999. Thermal decomposition and reconstitution of hydroxyapatite in air atmosphere. Biomaterials, 20: 1807-1813.

Lu, H., Qu, Z. and Zhou, Y. 1998. Preparation and mechanical properties of dense polycrystalline hydroxyapatite through freeze-drying. Journal of Materials Science: Materials in Medicine, 9: 583-587.

Metsger, D.S., Driskell, T.D. and Paulsrud, J.R. 1982. Tricalcium phosphate ceramic - a resorbable bone implant: review and current status. Journal of the American Dental Association, 105: 1035-1038.

Muralithran, G. and Ramesh, S. 2000. The effects of sintering temperature on the properties of hydroxyapatite. Ceramics International, 26: 221-230.

Newesely, H. 1977. High temperature behaviour of hydroxy- and fluorapatite. Crystal chemical implications of laser effects on dental enamel. Journal of Oral Rehabilitation, 4(1): 97-104.

Niihara, K. 1985. Indentation microfracture of ceramics-its application and problems. Journal of the Ceramic Society of Japan, 20: 12-18. 
Ramesh, S. 2004. A method for manufacturing hydroxyapatite bioceramic. Malaysia Patent No. PI. 20043325.

Ramesh, S., Tan, C.Y., Bhaduri, S.B. and Teng, W.D. 2007. Rapid densification of nanocrystalline hydroxyapatite for biomedical applications. Ceramics International, 33: 1363-1367.

Ramesh, S., Tan, C.Y., Bhaduri, S.B., Teng, W.D. and Sopyan, I. 2008. Densification behaviour of nanocrystalline hydroxyapatite bioceramics. Journal of Materials Processing Technology, 206: 221-230.

Ruys, A.J., Wei, M., Sorrell, C.C., Dickson, M.R., Brandwood, A. and Milthorpe, B.K. 1995. Sintering effect on the strength of hydroxyapatite. Biomaterials, 16: 409415.

Suchanek, W. and Yoshimura, M. 1998. Processing and properties of hydroxyapatitebased biomaterials for use as hard tissue replacement implants. Journal of Materials Research, 13: 94-117.

Suchanek, W., Yoshimura, M., Kakihana, M. and Yoshimura, M. 1997. Hydroxyapatite ceramics with selected sintering additives. Biomaterials, 18(13): 923-933.

Van Landuyt, P., Li, F., Keustermans, J.P., Streydio, J.M., Delannay, F. and Munting, E. 1995. The influence of high sintering temperatures on the mechanical properties of hydroxyapatite. Journal of Materials Science: Materials in Medicine, 6: 8-13.

Wang, C.K., Ju, C.P. and Chern Lin, J.H. 1998. Effect of doped bioactive glass on structure and properties of sintered hydroxyapatite. Materials Chemistry and Physics, 53: 138-149.

Wang, P.E. and Chaki, T.K. 1993. Sintering behaviour and mechanical properties of hydroxyapatite and dicalcium phosphate. Journal of Materials Science: Materials in Medicine, 4: 150-158.

Wei Chen, I. and Wang, X.H. 2000. Sintering dense nanocrystalline ceramics without final-stage grain growth. Nature, 404: 168-171.

Yamashita, K., Kitagaki, K. and Umegaki, T. 1995. Thermal Instability and Proton Conductivity of Ceramic Hydroxyapatite at High Temperatures. Journal of the American Ceramic Society, 78(5): 1191 - 1197.

Zhou, J., Zhang, X., Chen, J., Zeng, S. and DeGroot, K. 1993. High temperature characteristics of synthetic hydroxyapatite. Journal of Materials Science: Materials in Medicine, 4: 83-85. 